\title{
Impact of fetal presentation on neurodevelopmental outcome in a trial of preterm vaginal delivery: a nationwide, population-based record linkage study
}

\author{
Anna Toijonen $^{1}$ D $\cdot$ Seppo Heinonen ${ }^{2} \cdot$ Mika Gissler $^{3} \cdot$ Laura Seikku $^{4} \cdot$ Georg Macharey $^{4}$
}

Received: 6 May 2021 / Accepted: 13 July 2021 / Published online: 31 October 2021

(C) The Author(s) 2021

\begin{abstract}
Purpose To assess the risk of adverse neurodevelopmental outcomes at the age of four after an attempted vaginal delivery according to the fetal presentation in birth.

Methods This retrospective record linkage study evaluated the risks of cerebral palsy, epilepsy, intellectual disability, autism spectrum disorder, attention-deficit/hyperactivity disorder, and speech, visual, and auditory disabilities among preterm children born after an attempted vaginal breech delivery. The control group comprised children born in a cephalic presentation at the same gestational age. This study included 23803 singleton deliveries at gestational weeks $24+0-36+6$ between 2004 and 2014.

Results From 1629 women that underwent a trial of vaginal breech delivery, 1122 (66.3\%) were converted to emergency cesarean sections. At extremely preterm and very preterm gestations (weeks $24+0-31+6$ ), no association between a trial of vaginal breech delivery and neurodevelopmental delay occurred. At gestational weeks $32+0-36+6$, the risks of visual disability (aOR 1.67, CI 1.07-2.60) and autism spectrum disorders (aOR 2.28, CI 1.14-4.56) were increased after an attempted vaginal breech delivery as compared to vaginal cephalic delivery.

Conclusion A trial of vaginal breech delivery at extremely preterm and very preterm gestations appears not to increase the risk of adverse neurodevelopmental outcomes at the age of four. In moderate to late preterm births, a trial of vaginal breech delivery was associated with an increased risk of visual impairment and autism spectrum disorders compared to children born in cephalic presentation. A trial of vaginal preterm breech delivery requires distinctive consideration and careful patient selection.
\end{abstract}

Keywords Preterm delivery $\cdot$ Preterm labor $\cdot$ Breech presentation $\cdot$ Vaginal labor $\cdot$ Adverse outcome

Authorization to use of the data was obtained from the National Institute for Health and Welfare as required by the national data protection legislation in Finland (reference number THL/652/5.05.00/2017).

Anna Toijonen

anna.toijonen@helsinki.fi; anna.toijonen@gmail.com

Seppo Heinonen

seppo.heinonen@hus.fi

Mika Gissler

mika.gissler@thl.fi

Laura Seikku

laura.seikku@hus.fi

Georg Macharey

georg.macharey@hus.fi

\author{
Abbreviations \\ ICD-10 International Statistical Classification of \\ Diseases and Related Health Problems 10th \\ Revision; \\ OR Crude odds ratio; \\ $\mathrm{Cl}$ Confidence interval;
}

1 Department of Obstetrics and Gynecology, University of Helsinki, Riihiuunintie 12 c, 02620 Espoo, Finland

2 Department of Obstetrics and Gynecology, University Hospital (HUS), University of Helsinki, Haartmaninkatu 2, 00290 Helsinki, Finland

3 National Institute for Health and Welfare (THL), Helsinki, Finland

4 Department of Obstetrics and Gynecology, University Hospital (HUS), University of Helsinki, Haartmaninkatu 2, 00290 Helsinki, Finland 


$\begin{array}{ll}\text { CP } & \text { Cerebral palsy; } \\ \text { ID } & \text { Intellectual disability; } \\ \text { ASD } & \text { Autism spectrum disorder; } \\ \text { ADHD } & \text { Attention-deficit/hyperactivity disorder; } \\ \text { NIUT } & \text { Neonatal intensive care unit; } \\ \text { BMI } & \text { Body mass index; } \\ \text { PPROM } & \text { Preterm premature rupture of membranes; } \\ \text { aOR } & \text { Adjusted odds ratio }\end{array}$

\section{Introduction}

Preterm birth may significantly compromise the child's longterm neurodevelopment [1]. In Finland, preterm birth occurs in approximately five percent of singleton pregnancies [2], and depending on the gestational age, from 2.5 to $23.5 \%$ of these fetuses are in breech presentation [3].

A trial of preterm vaginal delivery in cephalic presentation is generally accepted management [4]. Nonetheless, the optimal delivery mode in preterm breech presentation is unknown, as the literature shows contradictory risks concerning neonatal mortality and morbidity [5-10]. In term pregnancies, vaginal breech delivery is widely accepted, with exceptions regarding pregnancies with certain risk factors such as oligohydramnios, fetal growth restriction, or otherwise compromised fetus [11-13]. Vaginal breech delivery at term is not associated with abnormal childhood neurodevelopment or with increased risk of epilepsy as compared to delivery by cesarean section $[14,15]$. However, several risk factors have been associated with a preterm breech presentation [3]. The risk factors for breech presentation vary according to gestational age [3], and many of these factors are linked to neonatal adverse outcomes, especially in vaginal delivery [16]. Several studies have demonstrated an increased risk of delayed intellectual or neuromotor development among preterm children born vaginally in breech presentation [5-7]. However, the findings are not solid as planned cesarean section has not improved the outcomes of preterm breech deliveries in all studies [9]. Due to the difficulties in arranging randomized controlled trials and the numerous confounding factors affecting observational studies, further studies are needed to provide evidence on the optimal management of preterm breech deliveries.

Our study investigates the impact of fetal presentation on neurodevelopmental outcomes at the age of four.

\section{Methods}

We conducted a population-based record linkage study on all children born between $24+0$ and $36+6$ gestational weeks from 2004 to 2014 in Finland. The Finnish Institute for Health and Welfare offered and authorized the data, as the Finnish national data protection law requires (reference number THL/652/5.05.00/2017). The data included the Medical Birth Register and the Hospital Discharge Register with the information on all surgical procedures and diagnoses (International Statistical Classification of Diseases and Related Health Problems $10^{\text {th }}$ Revision, ICD-10) in inpatient care (all hospitals) and outpatient care (public hospitals). All the maternity hospitals are obligated to serve the data to the national registers.

We excluded multiple gestations, term deliveries, and deliveries without the information on gestational age or fetal presentation. Only deliveries with a fetus either in breech or cephalic presentation were included. We limited the study to preterm deliveries of $\geq 24+0$ gestational weeks and excluded the pregnancies with placental abruption (ICD-10 O71.0, O71.1) or major congenital anomalies (as defined in the Register of Congenital Malformations), as such conditions and earlier gestational ages with lower viability of the infant might affect the results. As we aimed to evaluate the long-term effects of an attempted vaginal delivery according to the fetal presentation, we excluded the planned cesarean sections from our study.

We stratified the study population into three groups according to the World Health Organization's sub-categories of preterm birth: extremely preterm birth (gestational age $24+0-27+6$ ), very preterm birth (gestational age $28+0-31+6$ ), and moderate to late preterm birth (gestational age $32+0-36+6$ ). Each sub-category of preterm delivery was separately adjusted. The control groups comprised children born preterm in a cephalic presentation at comparable gestational ages. Odds ratios (OR) with $95 \%$ confidence intervals $(\mathrm{Cl})$ estimated the relative risk of neurodevelopmental disability at the age of four. The primary outcomes were neurodevelopmental disabilities: cerebral palsy (CP), epilepsy, intellectual disability (ID), autism spectrum disorder (ASD), attention-deficit/hyperactivity disorder (ADHD), speech, visual (ICD-10 H00-59), and auditory problems (ICD-10 H60-95). Late neonatal deaths at 28-364 days from birth were evaluated. As we aimed to examine the long-term effects of an attempted vaginal breech delivery, we did not include neonatal deaths or other shortterm outcomes in this research.

The analysis included the following maternal variables: age, smoking, parity, pre-pregnancy body mass index (BMI), history of cesarean section, hypo- and hyperthyroidism (ICD-10 E03, E05), pre-gestational diabetes (ICD-10 O24.0, $\mathrm{O} 24.1$ ), gestational diabetes (ICD-10 O24.4), preeclampsia, and pregnancy-induced hypertension (ICD-10 O13, O14). The following obstetric and fetal confounders were also acknowledged: oligohydramnios (ICD-10 O41.0), fetal sex, birthweight below third and 10th percentile of standard deviation, preterm premature rupture of membranes (PPROM) (ICD-10 O42), induction of labor, epidural analgesia (apart 
from epidural anesthesia in emergency cesarean section), and emergency cesarean section after a trial of vaginal breech delivery.

The statistical calculations were performed by SAS 9.4. We used a multivariate logistic regression model and chi-Squared test or Fisher's exact test when appropriate to adjust for confounders. $p$ values of $\leq 0.05$ were statistically significant.

\section{Results}

We analyzed 23803 preterm singleton deliveries. After exclusions, the study included 19430 preterm fetuses, and $1629(8.4 \%)$ of these were in breech presentation at the time of birth. The percentage of the breech presentation decreased from 25.1 to $6.5 \%$ by advancing gestational age. (Fig. 1).

The group of extremely preterm fetuses (gestational age $24+0-27+6)$ included 789 live births. An emergency cesarean section was performed in $68.7 \%(n=136)$ pregnancies with a fetus in breech presentation and in $47.9 \%(n=283)$ in cephalic presentation (OR 2.39; 95\% CI 1.70-3.36, p-value $<0.001)$. The breech deliveries in extremely preterm were less likely induced than cephalic deliveries (OR 0.23; $95 \%$ CI $0.08-0.67, p$ value 0.003$)$. Otherwise, the groups in extremely preterm did not differ significantly in maternal, fetal, or obstetric characteristics. Additional data on characteristics are given in Online Resource 1. At the age of four, the children with a trial of vaginal delivery in extremely preterm did not differ in neurodevelopment between the breech and cephalic presentation groups. The most common disabilities of these children were speech development delay (breech $9.1 \%$, cephalic $13.4 \%$ ) and cerebral palsy (breech $5.1 \%$, cephalic $4.4 \%$ ). Neonatal mortality within 28 to 364 days was $3.5 \%$ among the breech group and $2.7 \%$ in the cephalic group. The differences in mortality were statistically insignificant. (Table 1).

The group of very preterm birth (gestational age $28+0-31+6$ ) included 2861 deliveries. Of all very preterm fetuses in breech, $72.6 \%(n=291)$ were born by emergency cesarean section, and of the cephalic fetuses, $46.5 \%$ $(n=1145)$ (OR 3.03, 95\% CI 2.41-3.84, $p$ value $<0.001)$. In this very preterm group, the mothers with a fetus in breech presentation were more likely to be above 25 years old at

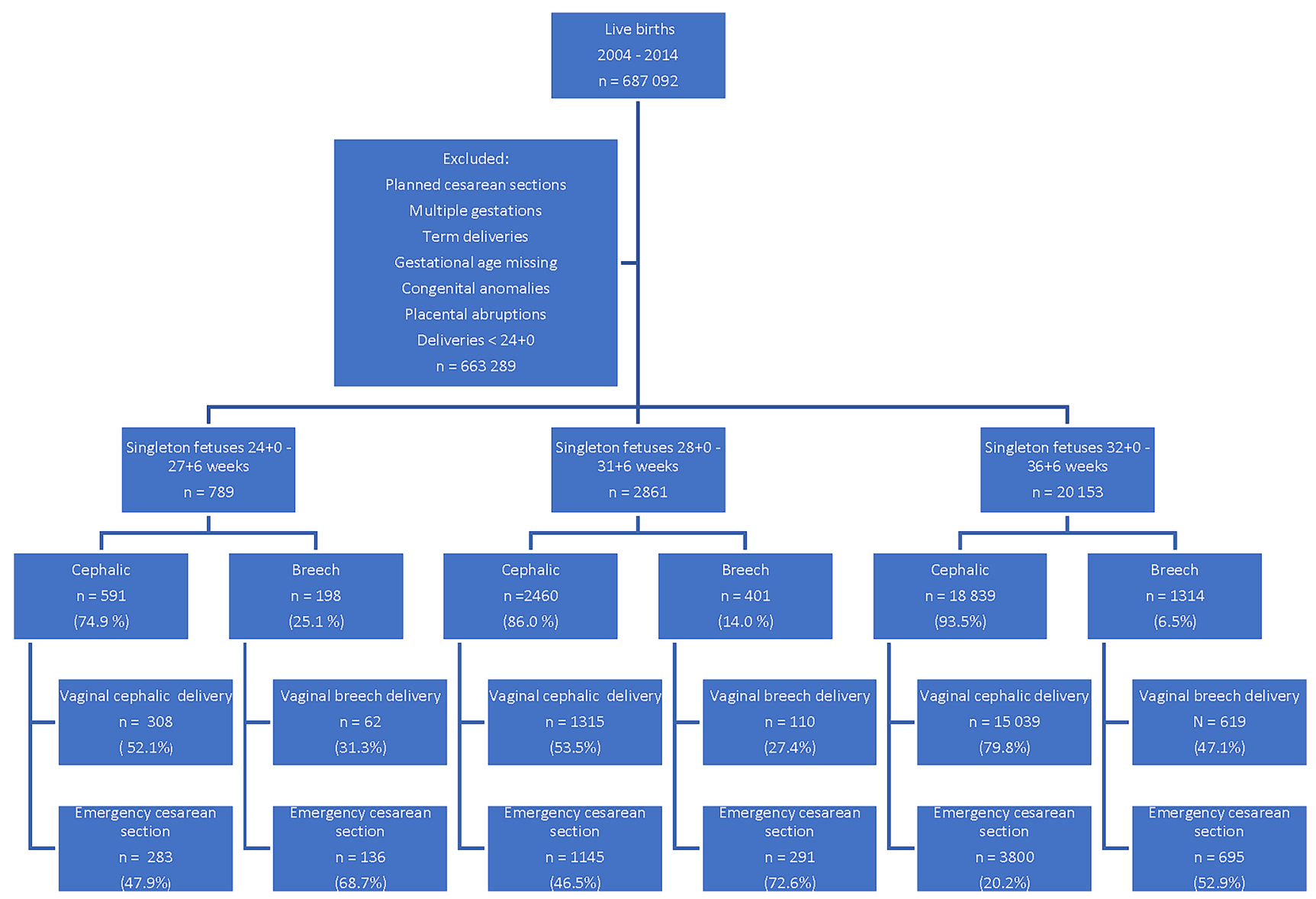

Fig. 1 A flowchart of the study population, preterm deliveries (vaginal and emergency cesarean sections) 2004-2014 in Finland 
Table 1 At the age of four, children's neurodevelopmental outcomes after an attempted vaginal delivery in $24+0$ to $36+6$ gestational weeks

\begin{tabular}{|c|c|c|c|c|c|c|c|c|c|}
\hline & \multicolumn{3}{|c|}{$24+0-27+6$} & \multicolumn{3}{|c|}{$28+0-31+6$} & \multicolumn{3}{|c|}{$32+0-36+6$} \\
\hline & $\begin{array}{l}\text { Breech } \\
n=198(\%)\end{array}$ & $\begin{array}{l}\text { Cephalic } \\
n=591(\%)\end{array}$ & $\begin{array}{l}\mathrm{aOR}(95 \% \\
\mathrm{CI})\end{array}$ & $\begin{array}{l}\text { Breech } \\
n=401(\%)\end{array}$ & $\begin{array}{l}\text { Cephalic } \\
n=2460(\%)\end{array}$ & $\begin{array}{l}\mathrm{aOR}(95 \% \\
\mathrm{CI})\end{array}$ & $\begin{array}{l}\text { Breech } \\
n=1314 \\
(\%)\end{array}$ & $\begin{array}{l}\text { Cephalic } \\
n=18839 \\
(\%)\end{array}$ & $\begin{array}{l}\mathrm{aOR}(95 \% \\
\mathrm{CI})\end{array}$ \\
\hline $\mathrm{CP}$ & $10(5.1 \%)$ & $26(4.4 \%)$ & $\begin{array}{l}1.31(0.61- \\
2.82)\end{array}$ & $12(3.0 \%)$ & $65(2.6 \%)$ & $\begin{array}{l}1.36(0.71- \\
2.57)\end{array}$ & $2(0.2 \%)$ & $81(0.4 \%)$ & $\begin{array}{l}0.25 \\
(0.06-1.11)\end{array}$ \\
\hline Epilepsy & $2(1.0 \%)$ & $12(2.0 \%)$ & $\begin{array}{l}0.42(0.09- \\
1.92)\end{array}$ & $8(2.0 \%)$ & $26(1.1 \%)$ & $\begin{array}{l}1.70(0.74- \\
3.91)\end{array}$ & $6(0.5 \%)$ & $119(0.6 \%)$ & $\begin{array}{l}0.77 \\
(0.33-1.78)\end{array}$ \\
\hline ID & $2(1.0 \%)$ & $9(1.5 \%)$ & $\begin{array}{l}0.61(0.13- \\
2.91)\end{array}$ & $4(1.0 \%)$ & $26(1.1 \%)$ & $\begin{array}{l}1.12(0.38- \\
3.31)\end{array}$ & $2(0.2 \%)$ & $64(0.3 \%)$ & $\begin{array}{l}0.43 \\
(0.10-1.79)\end{array}$ \\
\hline ASD & $2(1.0 \%)$ & $11(1.9 \%)$ & $\begin{array}{l}0.50(0.11- \\
2.31)\end{array}$ & $4(1.0 \%)$ & $19(0.8 \%)$ & $\begin{array}{l}1.51(0.49- \\
4.63)\end{array}$ & $10(0.8 \%)$ & $70(0.4 \%)$ & $\begin{array}{l}2.28 \\
(1.14-4.56)\end{array}$ \\
\hline Speech & $18(9.1 \%)$ & $79(13.4 \%)$ & $\begin{array}{l}0.65(0.38- \\
1.13)\end{array}$ & $17(4.2 \%)$ & $112(4.6 \%)$ & $\begin{array}{l}0.90(0.53- \\
1.53)\end{array}$ & $31(2.4 \%)$ & $473(2.5 \%)$ & $\begin{array}{l}0.91 \\
(0.63-1.33)\end{array}$ \\
\hline Visual & $6(3.0 \%)$ & $26(4.4 \%)$ & $\begin{array}{l}0.70(0.28- \\
1.76)\end{array}$ & $6(1.5 \%)$ & $55(2.2 \%)$ & $\begin{array}{l}0.66(0.28- \\
1.57)\end{array}$ & $24(1.8 \%)$ & $206(1.1 \%)$ & $\begin{array}{l}1.67 \\
(1.07-2.60)\end{array}$ \\
\hline Auditory & $0(0.0 \%)$ & $4(0.7 \%)$ & & $2(0.5 \%)$ & $13(0.5 \%)$ & $\begin{array}{l}0.94(0.21- \\
4.31)\end{array}$ & $3(0.2 \%)$ & $55(0.3 \%)$ & $\begin{array}{l}0.56 \\
(0.17-1.84)\end{array}$ \\
\hline ADHD & $1(0.5 \%)$ & $9(1.5 \%)$ & $\begin{array}{l}0.25(0.03- \\
1.98)\end{array}$ & $1(0.2 \%)$ & $18(0.7 \%)$ & $\begin{array}{l}0.30(0.04- \\
2.34)\end{array}$ & $7(0.5 \%)$ & $53(0.3 \%)$ & $\begin{array}{l}1.82 \\
(0.80-4.17)\end{array}$ \\
\hline $\begin{array}{l}\text { Child death } \\
28-364 \text { days }\end{array}$ & $0(0.0 \%)$ & $14(0.6 \%)$ & & & & & $3(0.2 \%)$ & $25(0.1 \%)$ & $\begin{array}{l}1.49 \\
(0.43-5.14)\end{array}$ \\
\hline
\end{tabular}

$24+0-27+6$ adjusted for emergency cesarean section and induction of labor

$28+0-31+2$ adjusted for maternal age $<25$, parity $\geq 3$, PPROM, induction of labor, epidural analgesia, and emergency cesarean section

$32+0-36+6$ adjusted for maternal age $<25$, smoking, primiparity, parity $\geq 3$, maternal $\mathrm{BMI}<20$, maternal hyperthyroidism, pre-gestational diabetes, gestational diabetes, oligohydramnios, female sex, birthweight $<10 \%$, PPROM, induction of labor, epidural analgesia, and emergency cesarean section

$C P$ cerebral palsy; $I D$ intellectual disability; $A S D$ autism spectrum disorder; $A D H D$ attention-deficit/hyperactivity disorder

the time of delivery and non-primipara than the mothers in the cephalic group. Multiparity ( $\geq 3$ deliveries) and PPROM were more common in the breech group than in the cephalic presentation group. Furthermore, the breech deliveries had fewer inductions and epidural analgesia compared to cephalic deliveries (Online Resource 2). The children born after a trial of vaginal breech delivery in this very preterm group had no increased risk of neurodevelopmental disabilities than the cephalic deliveries. Speech development problems (breech $4.2 \%$, cephalic 4.6\%) and cerebral palsy (breech 3.0\%, cephalic 2.6\%) appeared to be the most frequent problems among children in the study group. Among the breech children, no later deaths in 28-364 days occurred, whereas, among the children born in cephalic presentation, fourteen such deaths $(0.6 \%)$ occurred. The difference in mortality was not significant. (Table 1 ).

Our study enclosed 20153 moderate to late preterm deliveries (gestational age 32+0-36+6). An emergency cesarean section was the final mode of delivery in half of the breech pregnancies (52.9\%) and one-fifth of the cephalic ones (20.2\%) (OR 4.44, 95\% CI 3.96-4.98, $p$ value $<0.001$ ). Primiparity, maternal hyperthyroidism, oligohydramnios, PPROM, fetal female sex, and birthweight below $10 \%$ were more common in the breech presentation group than in the cephalic group in these moderate to late preterm deliveries. Accordingly, the mothers in the breech presentation group were more likely at least 25 years old, non-smokers, obese $(\mathrm{BMI} \geq 20)$, and non-diabetes (pre-gestational or gestational diabetes) than the mothers in the cephalic group. The breech deliveries were less likely induced or needed epidural analgesia compared to cephalic deliveries (Online Resource 3). Breech presentation in a trial of vaginal delivery doubled the risk of autism spectrum disorders (aOR 2.28, CI 1.14-4.56) and the visual defects were significantly increased (aOR 1.67, CI 1.07-2.60). Among the breech children born at moderate to late preterm gestations, three deaths $(0.2 \%)$ occurred in 28 to 364 days. There were twenty-five $(0.1 \%)$ late neonatal deaths in the cephalic group. (Table 1).

\section{Discussion}

We demonstrated that a trial of vaginal breech delivery at extremely preterm and very preterm gestations do not increase the risk of adverse neurodevelopmental outcome at the age of four. However, among moderate to late preterm 
births, a trial of vaginal breech delivery associates with an increased risk of visual impairment and autism spectrum disorders compared to children born in cephalic presentation.

In term delivery, studies have not connected vaginal breech delivery to a higher $\mathrm{CP}$ risk than in cephalic deliveries [20,21]. However, prematurity exposes the child to substantial morbidity and mortality [1]. The literature presents controversial results on short-term outcomes of vaginal preterm breech delivery. Schmidt and colleagues favored cesarean section for breech deliveries of less than 32 weeks of gestation to minimize neonatal morbidity [8]. In a Swedish study, a vaginal breech delivery at extremely preterm gestation increased the risk of neurodevelopmental delay [5]. Wood and colleagues reported similar results by demonstrating an association between extremely preterm vaginal breech delivery and cerebral palsy, as well as with severe neuromotor disability [6]. Furthermore, an extremely preterm vaginal breech delivery is connected to delayed neuropsychological development [7]. On the contrary, we found no excess/ additional risk of neuromotor developmental delay after a trial of vaginal breech delivery at extremely or very preterm gestations.

Our findings concerning visual impairments after a trial of vaginal breech delivery among moderate to late preterm births are in line with a previous study indicating an elevated risk of retinopathy of prematurity, chronic lung disease, and mortality in vaginal preterm breech delivery [17]. The most important risk factors related to visual problems such as retinopathy of prematurity are chronic intrauterine stress and asphyxia [18]. The increased risk of visual impairments among children born in breech may be explained by intrapartum complications such as difficulties at delivering the after-coming head. Furthermore, in moderate to late preterm pregnancies, breech presentation is associated with several obstetric problems such as oligohydramnios, PPROM, and growth restriction [3]. Various underlying complications may influence the risks of visual impairment and autism spectrum disorders detected in this study group. Moreover, visual symptoms are common among patients with autism spectrum disorders owing to the underlying central nervous system disability [19].

Our study showed no excess mortality among preterm children after a trial of vaginal breech delivery. This finding contradicts several other studies recommending cesarean section to reduce short-term mortality of preterm breech neonates $[5,17,22,23,24]$. Some studies align with our findings, indicating no excessive neonatal mortality after a trial of vaginal preterm breech delivery $[9,10]$.

In our study, epilepsy, intellectual disability, ADHD, speech, or auditory difficulties at the age of four were not increased among preterm children after a trial of vaginal breech delivery. In line with our findings, a recent study on vaginal preterm breech delivery found no association with neurodevelopmental impairment at the age of 2 years [9]. On the contrary, Källén and colleagues (2015) revealed a higher risk of intellectual developmental delay at 2.5 years in children born extremely preterm vaginally in breech presentation [5]. In our study, the breech delivery was more often converted to emergency cesarean sections than cephalic deliveries. This might have had a protective effect on the neurodevelopment as a cesarean section is readily performed if breech delivery is not proceeding expectedly. However, because the follow-up was until the age of four only, there is a possibility that the follow-up time was too short to detect minor differences in epilepsy, intellectual disability, ADHD, speech, or auditory difficulties detected later in life.

\section{Limitations and strengths}

Our study elucidated the long-term effects of vaginal preterm breech delivery during ten years with more than 20000 breech deliveries. Our study's major strengths are the long follow-up time and highly equal management of the deliveries and the neonatal and pediatric health care at the Finnish public hospitals.

Our study shows that breech children born after a trial of vaginal delivery at gestational ages between $32+0$ and $36+6$ weeks had an increased risk of visual impairment and autism spectrum disorders compared to the reference group comprising children born in cephalic presentation. However, it remains unclear whether the attempted vaginal breech delivery or the breech presentation itself increases the risk. The limitations of the study are related to the use of the registered data: We could not distinguish the severity of the visual disability, and we could not examine the duration of the trial of vaginal breech delivery or the delivery stage before converting into emergency cesarean section, since the data were not collected in the Medical Birth Register before 2017. Further caution in the interpretation of the analyses must be considered as multiple comparisons were made in small subgroups. There is a possibility that the study was underpowered to detect all the differences within the selected populations. However, this approach was justifiable because of the variations in the risk profiles between these subgroups. Some outcomes and analyzed factors were present only in a small population and thus broadened the confidence intervals.

\section{Conclusion}

Our study revealed key findings on long-term outcomes of preterm vaginal deliveries and strengthened the concept of vaginal breech births' safety. The results also show that the data from term deliveries cannot be directly used on preterm deliveries. 
The risks of visual impairment and autism spectrum disorders are increased among breech children after a trial of vaginal delivery at the gestational age between $32+0$ and $36+6$ weeks compared to the reference group with cephalic delivery. No association between a trial of vaginal breech delivery at gestational weeks $24+0-31+6$ and neurodevelopmental delay occurred. A trial of a vaginal breech delivery can be considered for individually selected preterm deliveries with the mother's consent.

Supplementary Information The online version contains supplementary material available at https://doi.org/10.1007/s00404-021-06146-z.

Authors contributions AT: Project development, manuscript writing. SH: Project development, manuscript editing. MG: Data management and analysis, manuscript editing. LS: Manuscript editing. GM: Project development, manuscript editing. All authors read and approved the final manuscript.

Funding Open Access funding provided by University of Helsinki including Helsinki University Central Hospital.

Availability of data and material The Finnish register data have been given for this specific study, and the data cannot be shared without authorization from the register keepers. More information on the authorization application to researchers who meet the criteria for access to confidential data can be found at Findata, the Health and Social Data Permit Authority: https://www.findata.fi/en/

Code availability SAS custom code cannot be shared publicly, but it is available on request from Mika Gissler (mika.gissler@thl.fi).

\section{Declarations}

Conflict of interest The authors declare that they have no conflict of interest.

Ethical approval This article does not contain any studies with human participants performed by any of the authors.

Informed consent statement The register-keeping organizations gave their permission to use their confidential health data in this study. No registered persons were contacted and thus, no consent for the participant was needed. The Finnish Institute for Health and Welfare authorized to use the data (reference number THL/652/5.05.00/2017).

Open Access This article is licensed under a Creative Commons Attribution 4.0 International License, which permits use, sharing, adaptation, distribution and reproduction in any medium or format, as long as you give appropriate credit to the original author(s) and the source, provide a link to the Creative Commons licence, and indicate if changes were made. The images or other third party material in this article are included in the article's Creative Commons licence, unless indicated otherwise in a credit line to the material. If material is not included in the article's Creative Commons licence and your intended use is not permitted by statutory regulation or exceeds the permitted use, you will need to obtain permission directly from the copyright holder. To view a copy of this licence, visit http://creativecommons.org/licenses/by/4.0/.

\section{References}

1. McCormick MC, Litt JS, Smith VC, Zupancic JAF (2011) Prematurity: an overview and public health implications. Annu Rev Public Health 32(1):367-379

2. Jakobsson M, Gissler M, Paavonen J, Tapper A-M (2007) The incidence of preterm deliveries decreases in Finland. BJOG An Int J Obstet Gynaecol 115(1):38-43. https://doi.org/10.1111/j.14710528.2007.01565.x

3. Toijonen AE, Heinonen ST, Gissler MVM, Macharey G (2020) A comparison of risk factors for breech presentation in preterm and term labor: a nationwide, population-based case-control study. Arch Gynecol Obstet 301(2):393-403. https://doi.org/10.1007/ s00404-019-05385-5

4. Sentilhes L, Sénat M-V, Ancel P-Y, Azria E, Benoist G, Blanc J et al (2017) Prevention of spontaneous preterm birth: Guidelines for clinical practice from the French College of Gynaecologists and Obstetricians (CNGOF). Eur J Obstet Gynecol Reprod Biol 210:217-224

5. Källén K, Serenius F, Westgren M, Maršál K (2015) Impact of obstetric factors on outcome of extremely preterm births in Sweden: prospective population-based observational study (EXPRESS). Acta Obstet Gynecol Scand 94(11):1203-1214. https://doi.org/10.1111/aogs.12726

6. Wood NS (2005) The EPICure study: associations and antecedents of neurological and developmental disability at 30 months of age following extremely preterm birth. Arch Dis Child - Fetal Neonatal Ed 90(2):F134-F140. https://doi.org/10.1136/adc. 2004.052407

7. Johnson S, Wolke D, Hennessy E, Marlow N (2011) Educational outcomes in extremely preterm children: neuropsychological correlates and predictors of attainment. Dev Neuropsychol 36(1):74-95. https://doi.org/10.1080/87565641.2011.540541

8. Schmidt S, Norman M, Misselwitz B, Piedvache A, Huusom LD, Varendi H et al (2019) Mode of delivery and mortality and morbidity for very preterm singleton infants in a breech position: a European cohort study. Eur J Obstet Gynecol Reprod Biol 234:96-102

9. Lorthe E, Sentilhes L, Quere M, Lebeaux C, Winer N, Torchin $\mathrm{H}$ et al (2019) Planned delivery route of preterm breech singletons, and neonatal and 2-year outcomes: a population-based cohort study. BJOG An Int J Obstet Gynaecol 126(1):73-82. https://doi.org/10.1111/1471-0528.15466

10. Kayem G, Combaud V, Lorthe E, Haddad B, Descamps P, Marpeau L et al (2015) Mortality and morbidity in early preterm breech singletons: impact of a policy of planned vaginal delivery. Eur J Obstet Gynecol Reprod Biol 192:61-65

11. Mattuizzi A (2020) Présentation du siege. Recommandations pour la pratique clinique du CNGOF - Épidémiologie, facteurs de risque et complications. Gynécologie Obs Fertil Sénologie 48(1):70-80

12. Kotaska A, Menticoglou S, Gagnon R, Farine D, Basso M, Bos $\mathrm{H}$ et al (2009) Vaginal delivery of breech presentation. Int $\mathbf{J}$ Gynecol Obstet 107(2):169-176. https://doi.org/10.1016/j.ijgo. 2009.07.002

13. Management of Breech Presentation: Green-top Guideline No. 20b. BJOG An Int J Obstet Gynaecol. 2017

14. Macharey G, Väisänen-Tommiska M, Gissler M, Ulander V-M, Rahkonen L, Nuutila M et al (2018) Neurodevelopmental outcome at the age of 4 years according to the planned mode of delivery in term breech presentation: a nationwide, population-based record linkage study. J Perinat Med 46(3):333-339. https://doi.org/10. 1515/jpm-2017-0127/html 
15. Krebs L, Langhoff-Roos J (2006) The relation of breech presentation at term to epilepsy in childhood. Eur J Obstet Gynecol Reprod Biol 127(1):26-28

16. Toijonen A, Heinonen S, Gissler M, Macharey G (2021) Risk factors for adverse outcomes in vaginal preterm breech labor. Arch Gynecol Obstet 303(1):93-101. https://doi.org/10.1007/ s00404-020-05731-y

17. Lodha A, Zhu Q, Lee SK, Shah PS (2011) Neonatal outcomes of preterm infants in breech presentation according to mode of birth in Canadian NICUs. Postgrad Med J 87(1025):175-179. https:// doi.org/10.1136/pgmj.2010.107532

18. Kim SJ, Port AD, Swan R, Campbell JP, Chan RVP, Chiang MF (2018) Retinopathy of prematurity: a review of risk factors and their clinical significance. Surv Ophthalmol 63(5):618-637

19. Little J-A (2018) Vision in children with autism spectrum disorder: a critical review. Clin Exp Optom 101(4):504-513. https:// doi.org/10.1111/cxo.12651

20. Bjellmo S, Andersen GL, Martinussen MP, Romundstad PR, Hjelle S, Moster D et al (2017) Is vaginal breech delivery associated with higher risk for perinatal death and cerebral palsy compared with vaginal cephalic birth? Registry-based cohort study in
Norway. BMJ Open 7(4):e014979. https://doi.org/10.1136/bmjop en-2016-014979

21. Bartlett D (2000) Early motor development of breech- and cephalic-presenting infants. Obstet Gynecol 95(3):425-432

22. Bergenhenegouwen LA, Meertens LJE, Schaaf J, Nijhuis JG, Mol BW, Kok M et al (2014) Vaginal delivery versus caesarean section in preterm breech delivery: a systematic review. Eur J Obstet Gynecol Reprod Biol 172:1-6

23. Robilio PA, Boe NM, Danielsen B, Gilbert WM (2007) Vaginal vs cesarean delivery for preterm breech presentation of singleton infants in California: a population-based study. J Reprod Med Obstet Gynecol 52(6):473-479

24. Reddy UM, Zhang J, Sun L, Chen Z, Raju TNK, Laughon SK (2012) Neonatal mortality by attempted route of delivery in early preterm birth. Am J Obstet Gynecol 207(2):117.e1-117.e8

Publisher's Note Springer Nature remains neutral with regard to jurisdictional claims in published maps and institutional affiliations. 